day hospital. There is regular feedback to all consultants on the progress of attenders. The atmosphere at the centres is non-medical with an emphasis on encouraging social interaction, self-confidence and increased independence. The life experiences and interests of volunteers and members can be drawn on. Volunteers visit the attenders at home when necessary.

A comparative costing per attender per day (including transport and meals, but excluding medical, community psychiatric nurse and social work costs) is:

Day hospital $£ 28$, Age Concern day centre $£ 9$.

Diagnostic groups are: psychoses (45\%); neuroses (40\%); mild dementia (15\%); living alone (50\%); and aged over $75(45 \%)$.

The advantages of the day centres are:

(a) relieves the day hospital at low cost to the health service

(b) non-hospital atmosphere reduces sickness behaviour

(c) personal attention of a high ratio of enthusiastic volunteers and members' choice of activity, e.g. craft, games, conversation, cookery, trips

(d) access when necessary to consultant, community psychiatric nurse, social worker, etc.

(e) community psychiatric nurse supports meetings to share information of members and volunteers about social facilities in the general community, resulting in $30 \%$ of patients moving on

(f) volunteers receive training-some of them have moved on to paid work with the elderly.

Tameside General Hospital

F. Oliver

Ashton-under-Lyne OL6 9RW

\section{Criteria for consultant posts}

\section{DeAr SirS}

The letter from Dr Lovett in your August issue struck a sympathetic chord in my mind as my late predecessor as Medical Administrator frequently accused the College of "moving the goalposts" in connection with the Approval Scheme.

Of course the College is quite properly concerned with defending and improving the practice of psychiatry and will thus inevitably be continually raising the criteria for training and for appointing to consultant posts. This can, however, cause some difficulty at a practical level if the guidelines are interpreted rigidly. Particularly in the less popular specialities of Psychiatry of Old Age and Mental Handicap, a situation may arise where the only candidate for a post fails to a greater or lesser degree to meet the College's criteria for appointment.
It seems to me that it may on such an occasion nonetheless be right to appoint such a candidate when not to do so will lead to no service being provided for that particular group of patients.

I would make a plea that the College should allow its advisers on Appointment Committees to exercise a reasonable amount of flexibility in these circumstances.

The Old Manor Hospital

D. J. S. WEST

Salisbury SP2 7EP

\section{Overseas doctors' training scheme}

\section{DeAR SIRS}

I very much welcome the Overseas Doctors' Training Scheme proposed in 'The Work of the Overseas Desk' (Psychiatric Bulletin, May 1989, 13, 260-262).

I have some reservations I would like to express about it.

Implementation of the scheme is subject to the following guidelines:

(a) no advertising for the SHO/Registrar post is necessary

(b) Advisory Appointments Committees are not necessary

(c) Health Authorities are able to agree contracts in advance of appointments.

The machinery for implementing the scheme involves:

(a) an overseas sponsor

(b) the Royal College of Psychiatrists which will identify training posts in the NHS for the candidate and make arrangements with the GMC for limited registration.

Professor Sims mentions that, "The whole scheme depends totally on the vindication of mutual trust between the candidate, the overseas sponsor, the College and the receiving training scheme organiser." I would like to be constructively cautious at that point for the sake of choosing the trainee who will benefit most from the scheme as well as for the sake of the post the trainee is going to fill, and would therefore raise two queries:

(a) Are overseas candidates getting equal chances?

(b) Are we in a position to select the best candidates?

In my view there are three possible approaches to selecting candidates:

(a) to arrange for the Appointing Committee to hold interviews once or twice a year in the overseas country in order to give equal opportunities for job competition among junior doctors and to reassure a good choice of an overseas doctor in the UK. Successful candidates should then be subject to a working contract with the Health Authority. This 
option is ideal, but might prove financially unrealistic.

(b) to rely on the recommendations of an individual sponsor, although objectivity regarding this method cannot be guaranteed

(c) to form a sponsoring organisation which consists of senior psychiatrists in the home country. This is part of the guidelines of the Royal College of Surgeons (Overseas Doctors Training Scheme, January 1989) which add that individual consultants and relatives of the candidate are not acceptable as sponsors.

Although I prefer the first option I opt for the last, due to its easy applicability.

I would welcome colleagues' suggestions and comments.

Springfield Hospital

London SW17 7DJ

\section{Dr Caldicott replies}

Professor Sims and I welcome Dr Abd's thoughtful letter concerning this training scheme, which constitutes part of the work of the Overseas Desk at the College (now renamed the Working Group for Overseas Liaison).

I should like to assure readers that we have been very careful to consider the points which Dr Abd so rightly raises. In particular, those overseas candidates who meet our criteria for acceptance onto the Scheme, which are stringent, currently have equal chances of placement on an approved UK training scheme. This may change if over-subscription occurs, when we will have to introduce a process of selection.

Ways and means by which selection of the best candidates can be made are currently being examined, and readers' views on how we could ensure that this occurs would be welcome. At the moment we have to leave the selection of suitable trainees to the overseas sponsors, who are carefully vetted. If mutual trust between the College and such a sponsor breaks down, e.g. if an unsuitable trainee is recommended, a sponsor will no longer be deemed acceptable either.

Ultimately, we may be able to hold "appointments committees" overseas, particularly if the question of financial support for the scheme, which is growing, is addressed constructively by the Department of Health. The College cannot afford to act as an em- ployment agency for Health Authorities to any great extent. Meanwhile, at least one Fellow of the College overseas in planning to conduct a competitive examination for potential trainees, which may be one way forward. However, it is important to note that the situation will vary according to the overseas country under consideration, as expectations and needs of the Scheme will vary among overseas sponsors and their trainees.

Finally, I should like to appeal to Tutors who have not, as yet, approached us with a view to taking an overseas trainee onto their scheme. We are running out of placements, and yes! the trainees can start their employment as an SHO.

Fiona CALdicott Sub-Dean Overseas Doctors Training Scheme

\section{Training experience in Australia}

DEAR SIRS

I read with interest the article 'An Australian Exchange' by Dr Harrison (Psychiatric Bulletin, July 1989, 13, 361-362).

I should like to point out that a one for one exchange (which is often difficult to arrange) is not necessary for overseas trainees who wish to have training experience in Australia. Instead, the Occupational Training Visa, arranged by the Australian Postgraduate Medical Federation is quite adequate; it is easily and rapidly obtainable and also enables trainees spouses (or companions) to work while here.

This hospital has developed a tradition of having one or two overseas trainees on its staff and it has been found to be a mutually rewarding experience.

I would suggest that trainees who may wish to spend a period in Australia should write to the hospital concerned enquiring about suitable vacancies. Psychiatric hospitals, many of which are university affiliated, have relatively larger numbers of trainees and thus tend to have more vacancies compared with the general hospital psychiatric units. I should be pleased to offer advice if needed.

Hillcrest Hosital

NORMAN JAMES Chief Executive Officer GPO Box 202

Adelaide

South Australia 5001 